Editorial

\title{
Imagining the Future of the Internal Combustion Engine for Ground Transport in the Current Context
}

\author{
José Ramón Serrano \\ CMT-Motores Térmicos, Universitat Politècnica de València, Camino de Vera, s/n 46022 Valencia, Spain; \\ jrserran@mot.upv.es; Tel.: +34-96-387-9657
}

Received: 20 September 2017; Accepted: 26 September 2017; Published: 28 September 2017

Internal Combustion Engines (ICEs) are the main propulsion systems for ground transport, both in on-road and off-road applications. By mid-2016, a special issue about ICEs for ground transport was announced, corresponding to this editorial. At this time, the forecast consensus was that it is not possible to replace ICEs in the powertrain of the majority of vehicles in the forthcoming decades, even considering the growth of plug-in electric and hybrid vehicles. The arguments for this consensus included the increasing demand of transport; the steep development of cleaner and more efficient ICEs; the availability of fossil fuels at good prices; and the high energy density of conventional fuels. Altogether, there seemed to be enough arguments supporting ICEs as the leading power plants propelling transport fleets worldwide.

In the last half year, the situation has changed. Mass-media are claiming the death of ICEs in the midterm. Political speakers of several G7 countries, such as France and the UK, have announced banning ICEs in their markets, in some cases as early as 2040. Big cities such as London, Paris, Madrid, and Berlin are considering severe limits on ICEs in their streets. What analysis can be taken from this situation?

\section{What Is the Problem with ICEs?}

The arguments in favor of actions against ICEs range respectively from: the mass-media's greed for novelty, i.e., the "end-of-oil-era with its old-fashion-ICEs" constitutes cool news; the need to reduce $\mathrm{CO}_{2}$ emissions when fighting against global warming; and the need to improve air quality in cities (mainly NOx and particle matter (PM) emissions).

A good deal of this noise around ICEs future has been amplified (or detonated) by the Diesel Gate. Such an awful management-and-engineering decision in a particular moment and a particular place has generated a butterfly effect worldwide in the automotive industry. Diesel Gate is forcing new regulations to obtain much cleaner ICE-powertrains. These new regulations will probably make the small and heavily downsized diesel engines, with traditional combustion and after-treatment approaches, not a good business for original engine manufacturers (OEMs) as some of them have recently declared; however, this does not mean the end of ICEs. As commonly occurs, past political underreactions with overly lenient regulations is forcing present media and political overreactions. Of course, new regulations that force ICE technology to be environmentally friendlier are always welcome. Yet, poorly justified bans, motivated by a poor diagnosis of the situation, can put at risk the jobs of many people and will not help at all, either to improve air quality or to mitigate global warming.

\section{What Is the Problem with Electric Powertrains?}

If one agrees that the need for transport will not disappear in the mid-to-long term, what is viewed as the replacement for cars with ICEs? Are they cars like those made by Tesla? Maybe the excellent marketing of Tesla has also contributed to the previous cocktail of confusion. Media loves the "New Steve Jobs" and they are ready to amplify any argument that can extrapolate the gorgeous evolution of 
cell phones to any other industrial sector i.e., powertrains. In the end, are not powertrains in the "same place" that they have been for the last 140 years or more? How can so old a concept be innovative? How can it be cool and techie if they continue to burn things inside the motors? Conclusion: Welcome to the "new electric motors and batteries" in cars that do not pollute at all! The bad news is that all this magic about electric cars is not true. Electric motors and batteries are not new, neither are they clean, and overall, they are not free of problems-specifically, two big problems.

First big problem is that the electric motor does not use a source of energy but a vector of energy. This is electricity, which does not exist as a source and cannot be accumulated; it has to be generated when consumed. Batteries were invented a long time ago as piles of chemicals, which can be easily transformed into electricity when needed. They are the leader technology to mobile systems that consume electricity. However, batteries are a totally immature technology in the range of power and energy needed for ground transport. So, they cannot compete successfully with fossil fuels. It does not matter what Mr. Musk says about Tesla's ion-lithium batteries in his speeches; this is the real situation. Toyota's research and development chief said few years ago that we needed a Novel Prize-winning type battery to make plug-in electric vehicles a real option for ICE car alternatives. And we have not heard even news of such a battery yet. Why is it a so immature technology? Because of five reasons or concepts: refueling (charging time); energy density; durability (life span); recycling; and materials supply. These arguments are ordered from worst to best from the point of view of customer perception, and are briefly discussed in the following:

- Refueling is unacceptably long for customers that like to use their cars out of cities and need to charge their batteries in the middle of a trip. Nobody offers/foresees solutions that safely charge the batteries of a car in less than 30 to $45 \mathrm{~min}$ without severe penalty to the batteries' life span. Imagine rush days such as holidays periods; refueling would become a nightmare when all batteries empty within a radius of about $150 \mathrm{~km}$ from big city centers. Only captive fleets or fix-route trips, which allow overnight charging, are free of this big issue of electric cars.

- Energy density is unacceptably low for out of city driving. When a vehicle's speed grows, the power consumption grows exponentially, and the mileage of electric cars reduces accordingly. On hilly roads, the problem grows linearly, and with loaded cars it grows once again. Batteries will last for less than $100 \mathrm{~km}$ of motorway driving, in a hilly place with the holiday luggage of a four-member family. Once again, only captive fleets or fixed-route trips are realistic options for these cars.

- Durability of batteries is mainly a question of carbonaceous material in the anode and cathode. Simply speaking, carbon nanostructures hold the ions during the electron exchange once and another time during electric to chemical transformation. This process deteriorates the carbonaceous material structure, leaving fewer "places" for ions and leading to reductions of the battery capacity, in the end making batteries non-useful. Carbon scientists worldwide are working hard to solve this problem, but no competitive solutions are ready or foreseen for the next two decades. It has been published that producing (without including recycling) a set of batteries from a certain model of Tesla car generates more $\mathrm{CO}_{2}$ emissions than driving a petrol engine for seven years. I wonder, will these battery sets last for seven years?

- Recycling is compulsory for the massive use of immature technologies such as batteries for powering cars. It is a costly process that is needed to avoid thousands of tons of electric waste that could be the short-term consequence of massive use of electric cars. It is not simple, nor cheap, nor efficient sometimes, according to what happens with actual e-waste from cell phones and computers. So, costs for users and the environment would grow exponentially with volume until the proper recycling of battery technologies is developed.

- Materials supply means mainly cobalt supply. Cobalt is needed for the anode of lithium ion batteries, and cobalt ore is mainly extracted from the Democratic Republic of Congo and mainly refined in China, so geopolitical issues and insecurity in the supply presents serious issues. However, not only cobalt, but also the largest lithium reserves are concentrated in only a 
few countries: Chile, Argentina, China (Tibet), Australia, and Bolivia-with further mining development-and its price is growing sharply. Therefore, geopolitical and supply cost issues with crude oil (nowadays mitigated thanks to fracking) can be easily transferred from Persian Gulf countries to South America's cone countries, as well as China, which controls a large share of refined cobalt and has large lithium proved reserves.

The second big problem is that we are not talking about technologies of information and communication (TICs) with an exponentially growing velocity of data management and transmission. We are talking about mass, energy, power, and the second principle of thermodynamics, which many people (especially journalist and politics) neglect. Just as the public understands the impact of gravity or friction forces in transport technologies, they should know how restrictive the second principle of thermodynamics is, and how true it is. The issue is that electricity has to be produced, that on average $90 \%$ is being produced from non-renewable sources of energy (with about $60 \%$ losses), and that it has to be transported (with subsequent $20 \%$ losses). Unfortunately, renewable sources are only about $10 \%$ of the world mix and we do not have a midterm forecast of this figure increasing significantly. In some countries like China, the USA, or Germany coal is still the largest source of energy in their mix of electricity production. Countries with real alternatives to $\mathrm{CO}_{2}$-emitting technologies are basically nuclear, such as France or Japan. So, it is clear that with the actual mix and from well-to-wheel, the electric powertrain technologies will not reduce global $\mathrm{CO}_{2}$ emissions if we do not go nuclear in a massive way. Maybe when nuclear fusion will be an economically feasible alternative will this second big problem will disappear. In the time being, gaseous emissions are only being delocalized from cities to big power plant locations. Unfortunately, the global warming issue cannot be delocalized and atmospheric phenomena do not know about borders, as acid rains and clouds of particulate matter (PM) have proven repeatedly.

\section{What Is Good with Internal Combustion Engines (ICEs)?}

Forthcoming limitations in green-house gases $\left(\mathrm{CO}_{2}\right)$, gaseous pollutants, and noise emissions will be more and more severe; forcing engine OEMs and the automotive industry to invest in more innovative and sophisticated technologies for their abatement. Real Driving Emissions (RDE) regulations are being adopted in major economic areas, which means additional challenges to vehicle OEMs, since this greatly widens the ICE operative range at which pollutants emissions must be kept below homologation limits. This scenario offers exciting opportunities to engineers and researchers to convince OEMs adopting already investigated new ideas and innovative technologies. A revolution is coming, concerning traditional petrol and diesel engines, and the limits between both are quickly vanishing as deeper knowledge and more control of the combustion process are gained. A case was recently announced by Mazda concerning its new homogeneous charge compression ignition (HCCI) engine, which will go into market in 2019. New cycles, new concepts, and more complex architectures are emerging. Propulsion power plants, based on ICEs, are becoming a complex mix of machines, far beyond the traditional reciprocating mechanism. Turbochargers, superchargers, organic-Rankine-cycles (ORC), and hybridization are part of the ICE environment, all dedicated to extract every Watt of power from liquid fuels. Outside the cylinders, in the cold pipe end, the extensive use of exhaust gasses after-treatment introduces new paradigms in the global design of power plants based on ICEs. In this new light, old ideas are being revised with the revival of two stroke engine concepts. Catalyst chemistry research is continuously offering exciting possibilities for cleaning exhaust gases up to unbelievable limits. Nowadays, nothing is too innovative or too risky to cope with the expected midterm demand of cleaner and more efficient ICEs. Finally, fossil fuels are cheap and available. Oil-peak is no longer a topic of discussion since fracking technology has offered a new paradigm, making the USA the biggest fossil fuel producer in the world.

As a guest editor, I take this opportunity to sincerely thank the scientific and technically advanced works that have been published in the present special issue. They highlight some of the abovementioned topics on ICEs. They are clear examples of the silent revolution that researchers 
worldwide are casting around a more than 140-year-old machine, which is younger and more technically promising than ever. The works published prove that both ICEs' fuel consumption and pollutants emissions (especially NOx and PM) can be significantly reduced with laboratory-proven technologies. Therefore, it is only a matter of cost and scale investments to make these technologies fully commercial.

\section{What Is Fantastic about Internal Combustion Engines (ICEs)?}

That ICEs emit locally gaseous pollutants and $\mathrm{CO}_{2}$ is accepted as written in stone, just as it is accepted that electric cars do not. Summarizing this is the big argument for the replacement of ICEs. What if the situation is somehow the opposite?

If we talk well-to-wheel, neither the battery production nor the electricity production is free of $\mathrm{CO}_{2}$ and pollutants emissions. Electricity production causes much greater pollutants emissions than liquid fossil fuels production, since it is an energy vector that is more difficult to obtain and transport. In conclusion, the statements made in the previous paragraph are not so true for electric cars. One can say that, similarly, cars with ICEs generate emissions during their production. Yes, it is true, but one should admit that at principle no more than batteries and electric motors. What can ICEs do further to increase air quality? It is well known that a modern Euro6 ICE can clean the air from PM and smog in heavily polluted cities such as Teheran or Beijing. Technology is available and research is ongoing, both in terms of highly turbocharged HCCI engines and after-treatment of exhaust gasses, to allow next-generation ICEs to act as moving vacuum cleaners of these pollutants through the city streets. This is something that electric motors with batteries cannot do. Political action is needed to renew worldwide transport fleets and to promote in all countries the same standards in ICEs emissions as are upheld in the USA, Japan, or Europe. Also, it is necessary to apply certification tests to real driving conditions, as is being done in these economical areas, in order to ensure effective regulations on pollutants emission reductions.

Concerning $\mathrm{CO}_{2}$ emissions problems, it is good to be reminded that the transport contribution to worldwide $\mathrm{CO}_{2}$ emissions is merely $10 \%$. So, a massive change to electric cars, for only $10 \% \mathrm{CO}_{2}$ share, does not seem enough to mitigate global warming. Industry, farming, central heating, and air conditioning in homes do the rest. Electric cars do not emit $\mathrm{CO}_{2}$ only if electricity comes from renewable or nuclear sources. If one imagines this will be the standard in the mid-to-long term, could ICEs do as well as this? The answer is yes, if we use synthetic fuels coming from $\mathrm{CO}_{2}$ Capture and Use (CCU). There are a number of projects in Switzerland, Germany, and Canada focused on CCU. They are transforming $\mathrm{CO}_{2}$ directly taken from the air into a liquid fuel called e-Diesel. This is conducted through hydrogenation and following the $\mathrm{CO}$ Fisher-Tropsch (FT) process. There are also projects of pumping $\mathrm{CO}_{2}$ captured from power plants into oil wells to convert it into $\mathrm{CO}_{2}$ neutral oil. There are even projects of cars capturing their own $\mathrm{CO}_{2}$ emissions (joint with the $\mathrm{CO}_{2}$ from the atmosphere) and performing on-board conversion into $\mathrm{CO}_{2}$ neutral fuel. That way, self-CCU is contributing to a slight reduction of $\mathrm{CO}_{2}$ in the atmosphere. If the fuels used in these $\mathrm{CO}_{2}$ self-capturing cars were mostly bio-fuels, as is the case in Brazil, this represents an efficient way of removing $\mathrm{CO}_{2}$ from the atmosphere. One can say that this will be done only with the expense of big quantities of thermal energy. Yes, but about $60 \%$ of fuel energy is rejected in the engines as thermal energy; thus, we can partially re-use it in this $\mathrm{CO}_{2}$ capturing process. Either way, one can imagine that any reasonable increment in fuel consumption for this cause could be accepted by customers or compensated with lower bio-fuel taxes. In conclusion, if we look for a change of paradigm, why do not change our cars to be like moving $\mathrm{CO}_{2}$ capturers through the roads? They will remove the other $90 \%$ of $\mathrm{CO}_{2}$ (from industry, farming, etc.) that ground transport is not producing. Also, this is something that electric motors with batteries cannot do.

Public money and governments efforts could promote research in these directions instead of picking winners for an uncertain future. Direct subsidies to any industry or technology and banning others, without scientifically clear arguments, is the kind of risky exercise that has never being 
successful, at least in the last hundreds of years. Listening to scientists and promoting research activities, whatever the research field-for example those published in this special issue or pointed to in this editorial-always have brought great benefits for future generations and normally have been cheaper. Many say that it is not enough to reduce $\mathrm{CO}_{2}$ emissions to stop global warming. It is pointed out that we need to remove from atmosphere the excess of $\mathrm{CO}_{2}$ previously emitted. Why not push harder research on ideas such as the $\mathrm{CO}_{2}$ removing engines? Why do CEOs from ICEs' OEMs not buy this fantastic opportunity to lead in the marketing battle and make ICEs the good guys of the film?

Conflicts of Interest: The author declares no conflict of interest.

(C) 2017 by the author. Licensee MDPI, Basel, Switzerland. This article is an open access article distributed under the terms and conditions of the Creative Commons Attribution (CC BY) license (http://creativecommons.org/licenses/by/4.0/). 